\title{
Fractographic Analysis of GTAW Robotic Welded Joints Fractured under Stress in Experimental HSLA Cr-Ni Steel
}

\author{
Leyva L. Orión, Rosel P. Graciela, and H. Gamez-Cuatzin
}

\begin{abstract}
The welding current (A), arc voltage (V) preheating $\left({ }^{\circ} \mathrm{C}\right)$, travel speed $\left(\mathrm{mm} \cdot \mathrm{min}^{-1}\right)$ and net heat input $\left(Q_{\text {net }}\right)$ were evaluated, on the strength and morphology of the fracture in experimental HSLA Cr-Ni steel welded joints, with commercial (ERS70S-6) filler metal and robotic GTAW technique. The samples were characterized by uniaxial stress tests, stereoscopy and Digital Image Processing (DIP). The results showed that the resistance to fracture of the experimental steel was exceeded by $18.39 \%$ by applying $Q_{\text {net }} 0.520\left(\mathrm{~kJ} \cdot \mathrm{mm}^{-1}\right)$ and the combination of: $200 \mathrm{~A}, 12.7 \mathrm{~V}, 25^{\circ} \mathrm{C}$ and $180 \mathrm{~mm} \mathrm{~min}^{-1}$, which influenced the ductile fracture morphology and topology. While the low Qnet $\left(0.200-0.208 \mathrm{~kJ} \cdot \mathrm{mm}^{-1}\right)$ favors instantaneous deformation of the welded joints with fracture in the weld bead as the major defect.
\end{abstract}

Keywords - digital fractography, digital image processing (DPI), resistance to fracture, robotic GTAW.

\section{INTRODUCTION}

High-strength steels have been an option for armor plating in the ballistics industry and used in the core material of projectiles, due to their low cost and mechanical properties [1]. Among the properties that should be highlighted are: strength, strain hardening rate, toughness and, therefore, resistance to fracture $\left(\mathrm{S}_{\mathrm{f}}\right)$. Automotive armor requires welded joints that guarantee the integrity of the assembled parts, thus, making it crucial to analyze them, identify any faults and determine their origin, which is of the utmost importance to establish in ballistic components [2]. The mechanical resistance of High Strength and Low Alloy (HSLA) to Cr-Ni steels is directly associated with their alloying elements; in particular to $\mathrm{Cr}$ and $\mathrm{Ni}$, which are essential to increase their mechanical resistance [3], since $\mathrm{Cr}$ increases the resistance to corrosion of alloys in oxidizing media and Ni produces greater elongation under stress and improves resistance to fracture (compared to $\mathrm{C}$ or low alloy steels) [4]. For the assembly of parts in HSLA steels, it is common to use Gas Tungsten Arc Welding (GTAW) because it is free of slag, presents less impurities and porosity and high production with welding robots [5] [6] [7]. This process maintains high temperatures for a longer time and the heat input is higher compared to others [8], consequently, it is important to evaluate the $Q_{\text {net. }}$.

A study on tensile fracture in welded joints in API-5LX52 line pipe steel, by means of an artificially aged double pass SAW process, showed the existence of micro-voids

Submitted on October 25, 2021

Published on November 15, 2021.

Leyva L. Orion, Tecnológico Nacional de México, México.

(e-mail: carlocorinto84@gmail.com)

Rosel P. Graciela, Tecnológico Nacional de México, México.

(e-mail: grace.ros10@gmail.com) associated with micro-cavities present in the morphology of the ductile fracture, which was characterized with stress testing, microscopy and SEM [9]. In subsequent research on the aforementioned welded joints in API-5L-X52 pipes, the authors [10] used digital processing in fractographic images by segmentation and "Top-Hat" transform; finding more number of micro hollows in the ductile failure (equivalent to $2 \mu \mathrm{m})$. With this methodology, a significant difference was obtained between manual experimental counting and digital image processing, which showed a $3.4 \%$ improvement in the precision counts of microholes associated with the fracture.

Similarly, [11] they used digital fractographic analysis to evaluate the influence of heat input on fracture in the reheated HAZ of semi-automatic GMAW-P multilayered welded joints in HSLA steel. With digitally processed fractography, it was possible to identify well-defined black areas associated with ductile fracture, as well as rigid black lines that corroborated secondary cracking and presence of micro dimples.

Another significant study was carried out [12], in which the effect of heat input $\left(Q_{\text {net }}\right)$ was analyzed in GTAW-P robotic HSLA Cr-Ni steel welded joints with ERS70S-6 filler metal (chemical characteristics similar to those of the present study), where it was shown that the $Q_{\text {net }} 0.600$ $\mathrm{kJ} \cdot \mathrm{mm}^{-1}$ favored the mechanical properties to traction of the welded joint and was shown to be free of defects.

In recent research [13], an exploration was performed with different DPI techniques, such as pre-processing, noise elimination, contrast enhancement, edge detection, achieving a qualitative and quantitative review of the type and extent of corrosion, consequently, adding elements to characterize the degradation suffered by the evaluated material.

As documented, the welding area is more susceptible to the presence of failures due to changes in the state of matter that result in microstructural modifications and thermal affectations. However, there are minimal contributions on DPI in fractography (as a characterization method) along with mechanical analysis of GTAW robotic experimental HSLA Cr-Ni steel welded joints, whose purpose is ballistic protection of automotive structures.

The objective of this research is to establish the best combination of essential parameters of the robotic GTAW [5] process and determine under which parameters the safety of experimental steel welded joints is compromised, categorizing the best mechanical behavior, the origin of the

Gámez-C. Hugo, Centro de Ingeniería y Desarrollo Industrial (CIDESI), México.

(e-mail: hgamez ${ }^{@}$ cidesi.edu.mx). 
failure, the crack zones and the propagation mechanism, whose relevance is the digital analysis of the fracture, revealing the its characteristics in the experimental HSLA $\mathrm{Cr}-\mathrm{Ni}$ steel welded joints with commercial filler metal.[14] [15] [16] [17].

\section{EXPERIMENTAL DEVELOPMENT}

HSLA steel in original condition was machined by abrasive waterjet cutting with Mitsubishi Electric supreme
DX510 machine with dimensions of $110 \times 110 \times 4 \mathrm{~mm}$ in length, width and thickness respectively. The chemical composition was obtained by means of optical emission spectrometry in Spectrolab equipment according to ASTM E415-14 [18]. The weight percentages per element present in the base metal and ER70S-6 wire are shown in Table I. Based on this, equation 1 [7] was applied and the $\mathrm{C}_{\text {eq }}$ was calculated.

\begin{tabular}{|c|c|c|c|c|c|c|c|c|c|}
\hline \multicolumn{10}{|c|}{ TABLE I: CHEMICAL COMPOSITION OF HSLA CR-NI TEST STEEL AND ER70S-6 FILLER METAL } \\
\hline \multirow{2}{*}{ Material } & \multicolumn{9}{|c|}{ Element $(\mathrm{Wt} \%)$} \\
\hline & $\mathrm{C}$ & $\mathrm{Mn}$ & $\mathrm{Si}$ & $\mathrm{Ni}$ & $\mathrm{Cr}$ & Mo & $\mathrm{P}$ & S & $\mathrm{C}_{\mathrm{eq}}$ \\
\hline $\begin{array}{c}\text { HSLA } \\
\text { experimental steel }\end{array}$ & 0.28 & 1.34 & 0.42 & 1.82 & 0.53 & 0.54 & 0.01 & 0.00 & 0.86 \\
\hline ER70S-6 & 0.10 & 1.62 & 0.97 & 0.15 & 0.15 & 0.15 & 0.02 & 0.02 & 0.49 \\
\hline
\end{tabular}

$$
\left.C_{e q}=C+\overline{\frac{M n}{6}}+\overline{\left(\frac{C r+M_{0}}{5}+V\right.}\right)+\left(\frac{C_{u}+N_{i}}{15}\right) \ldots
$$

The mechanical properties of the ER70S- 6 wire and the experimental HSLA Cr-Ni steel under original conditions are presented in Table II. The fracture resistance $\left(\mathrm{S}_{\mathrm{f}}\right)$ was $56.1 \%$ higher in the HSLA steel than in the ER70S-6 wire, which complies with the AWS A5.18 specification [19]. The ultimate tensile strength (UTS) was higher for the experimental HSLA Cr-Ni steel, however, it showed 50\% lower ductility than the commercial filler metal.

TABLE II: MECHANICAL PROPERTIES OF HSLA STEEL AND ER70S-6 WIRE

\begin{tabular}{ccccc}
\multicolumn{5}{c}{ WIRE } \\
\hline \hline \multirow{2}{*}{ Material } & $\begin{array}{c}\mathrm{S}_{0} 0.2 \% \\
(\mathrm{MPa})\end{array}$ & $\begin{array}{c}\text { UTS } \\
(\mathrm{MPa})\end{array}$ & $\begin{array}{c}\mathrm{S}_{\mathrm{f}} \\
(\mathrm{MPa})\end{array}$ & $\begin{array}{c}\text { Elongation } \\
(\%)\end{array}$ \\
\hline HSLA steel & 781 & 1252 & 1033 & 11 \\
ER70S-6 wire & 375 & 745 & 580 & 22 \\
\hline \hline
\end{tabular}

Table III shows the essential parameter combinations [6] selected for the present study in four welded joints and their respective $\mathrm{Q}_{\text {net. }}$

\begin{tabular}{cccccc}
\multicolumn{5}{c}{ TABLE III: PARAMETER COMBINATION UNDER STUDY } \\
\hline \hline Specimen & $\begin{array}{c}\text { Welding } \\
\text { Current } \\
(\mathrm{A})\end{array}$ & $\begin{array}{c}\text { Arc } \\
\text { voltage } \\
(\mathrm{V})\end{array}$ & $\begin{array}{c}\text { Assembly } \\
\text { temperatur } \\
\mathrm{e}\left({ }^{\circ} \mathrm{C}\right)\end{array}$ & $\begin{array}{c}\text { Travel } \\
\text { speed } \\
\left(\mathrm{mm} \cdot \mathrm{min}^{-1}\right)\end{array}$ & $\begin{array}{c}\mathrm{Q}_{\text {net }} \\
\left(\mathrm{kJ} \cdot \mathrm{mm}^{-1}\right)\end{array}$ \\
\hline GT19 & 200 & 12.7 & 25 & 180 & 0.52 \\
GT23 & 250 & 13.3 & 87.5 & 330 & 0.37 \\
GT13 & 200 & 13.5 & 150 & 480 & 0.20 \\
GT12 & 200 & 13.1 & 25 & 480 & 0.20 \\
\hline \hline
\end{tabular}

The welding coupons were prepared with square bezel, 120 grit $\mathrm{Al}_{2} \mathrm{O}_{3}$ sandpaper roughing and residue cleaning with industrial acetone, to stabilize the electric arc.

They were fixed in position $1 \mathrm{G}$ plane with $0.9 \mathrm{~mm}$ root opening [6] (Fig. 1) applying direct flame preheating to commercial butane gas (mixture of $\mathrm{C}_{4} \mathrm{H}_{10} 60 \%, \mathrm{C}_{3} \mathrm{H}_{8} 9 \%$, $\left.\left(\mathrm{H}_{3} \mathrm{C}\right)-\mathrm{CHCH}_{3}-\mathrm{CH}_{3} \quad 30 \%, \quad \mathrm{C}_{2} \mathrm{H}_{6} \quad 1 \%\right)$, verifying the temperature with a laser pyrometer, before each experimental run. Subsequently, double-pass GTAW was performed with a Fanuc Arc Mate 120ic robotic arm, 90 torch angle, $\mathrm{W} \mathrm{C}_{\mathrm{e}} \mathrm{O}_{2} 2 \%$ electrode $(\varnothing 3.2 \mathrm{~mm})$ with linear displacement, applying ER70S-6 filler metal at
$7.2 \mathrm{~mm} \mathrm{~min}^{-1}$ feed rate, inert gas protection of $99.99 \% \mathrm{Ar}$ with flow of $14 \mathrm{~L} \cdot \mathrm{min}^{-1}$ according to the Welding Procedure Specification (WPS) [5], [6].

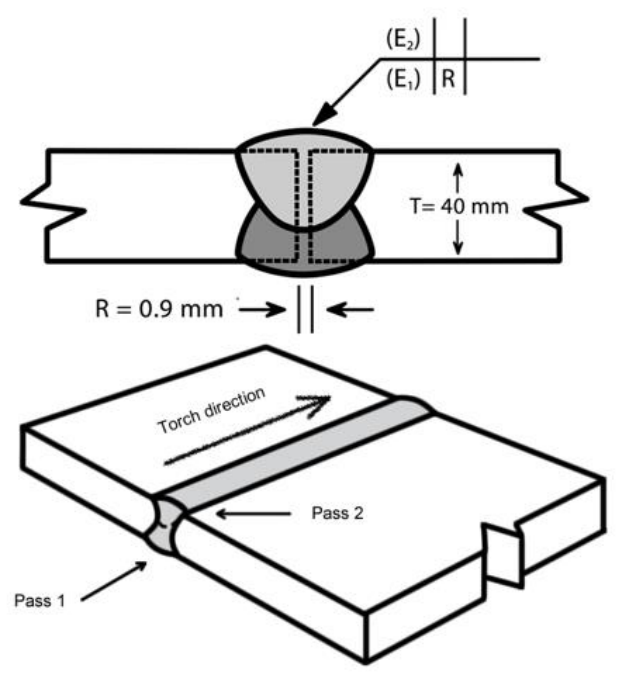

Fig. 1. Joint design with square bevel $\left(90^{\circ}\right), 1 \mathrm{G}$ position, double bead weld, according to WPS [6]

$Q_{\text {net }}$ was calculated by equations (2) and (3) [7]:

$$
Q_{n e t}=\eta \mathrm{H}
$$

where $\mathrm{Q}_{\text {net }}=$ net heat input $\left(\mathrm{kJ} \cdot \mathrm{mm}^{-1}\right)$; $\eta=$ heat transfer efficiency 0.65 [12].

$$
H=\frac{E I}{W}
$$

where $\mathrm{H}=$ arc energy input $\left(\mathrm{kJ} \cdot \mathrm{mm}^{-1}\right), \mathrm{E}=$ Voltage $(\mathrm{V}), \mathrm{I}=$ Current (A), W = welding speed $\left(\mathrm{mm} \cdot \mathrm{min}^{-1}\right)$ [20] [21].

The mechanical characterization was carried out with reduced specimens of $100 \mathrm{~mm}$ in total length, according to ASTM E-8-13 [22] with reduced section length of $32 \mathrm{~mm}$, width of $6 \mathrm{~mm}$ and calibrated length of $25 \mathrm{~mm}$, having the welded joint in the center (Fig. 2). Uniaxial stress tests were performed on universal machine (Instron 4482) with a strain rate of $3.6 \times 10^{-4} \mathrm{~s}^{-1}$ a $25^{\circ} \mathrm{C}$. 


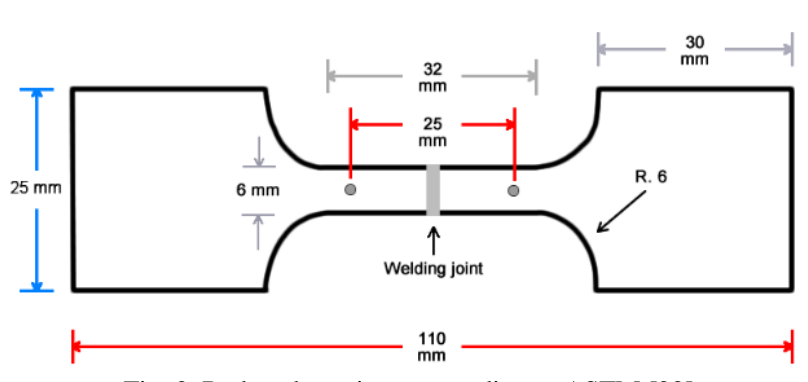

Fig. 2. Reduced specimen according to ASTM [22].

Once the specimens were fractured, they were cleaned with compressed air to remove dust particles and underwent ultrasonic cleaning with methyl alcohol for $10 \mathrm{~min}$. The fractography was performed on a STEMI 2000-C stereoscope with an Axiovert ERc 5s digital camera (both from Carl Zeiss) at 6.5x to analyze the base metal, the HAZ, the weld bead and thereby, determine the fault origin. Four fractographs per specimen (two longitudinal and two transverse) were taken for complete analysis of the fractured specimens. The digital analysis was performed with the Axio Rel software Version 4.8 from Carl Zeiss. DPI was performed together with Image Pro software.

The first step for DPI was performing Low-level image processing (preprocessing) of the specimens exposed to the stereoscope, later segmentation, "Top-Hat" and the discrete Fourier and Wavelet transforms were performed [10], [13].

\section{RESULTS}

The mechanical strength results obtained from the uniaxial stress mechanical tests of the robotic GTAW welded joints are shown in stress-strain curves (S-e) accompanied by the curve of the steel in receiving conditions (Fig. 3a). Where two types of dissimilar behavior can be observed: TYPE 1 with fracture in base metal, adequate fracture stress and good mechanical performance associated with the medium and high values of $Q_{\text {net }}(0.374$ $\left.0.523 \mathrm{~kJ} \cdot \mathrm{mm}^{-1}\right)$ and TYPE 2 whose fracture occurred in the weld metal and showed undesirable mechanical behavior in any component [5], [6], [23], [24] (Table IV).

TABLE IV: COMPARATIVE BOARD OF THE 4 SELECTED SPECIMENS, WHERE FRACTURE ZONE AND TIME ARE OBSERVED

\begin{tabular}{ccccc}
\hline \hline Specimen & Behavior & $\begin{array}{c}\text { Fracture } \\
\text { zone }\end{array}$ & $\begin{array}{c}\text { Crack time } \\
\text { (seconds) }\end{array}$ & $\mathrm{S}_{\mathrm{f}}(\mathrm{MPa})$ \\
\hline GT19 & 1 desired & Base metal & 43.48 & 1223 \\
GT23 & 1 desired & Base metal & 42.17 & 1204 \\
GT13 & 2 faulty & Weld & 6.20 & 166 \\
GT12 & 2 faulty & Weld & 14.38 & 485 \\
\hline \hline
\end{tabular}

TYPE1 specimens were categorized based on fracture resistance, followed by fracture resistance time. The specimen identified as GT19 had the best behavior before the fracture of $S_{\mathrm{f}} 1223 \mathrm{MPa}$ and average deformation of $12.5 \%$. As documented [12] values close to $0.523 \mathrm{~kJ} \cdot \mathrm{mm}^{-1}$ favor mechanical resistance of welded joints, achieving complete penetration and fusion with the filler metal, resulting in an adequate recrystallization of the metals that prompted an integral welded joint, free of defects in the conventional and preheated HAZ [7] adequately resisting the uniaxial tensile force.
Of the pieces studied, the second with the best fracture behavior was the specimen identified as GT23, which suffered fracture in the base metal at $1204 \mathrm{MPa}$, a phenomenon related to average $\mathrm{Q}_{\text {net }} 0.374 \mathrm{~kJ} \cdot \mathrm{mm}^{-1}$ (Fig. $3 \mathrm{~b}$ ), consequence of the combination of parameters: $250 \mathrm{~A}$, 13.3 V, $87.5^{\circ} \mathrm{C}$ and $330 \mathrm{~mm} \cdot \mathrm{min}^{-1}$.

The former benefited from the response of the welded joints to uniaxial tensile stress, showing an increase of $16.55 \% \mathrm{~S}_{\mathrm{f}}$ and $2 \%$ in UTS with regard to alloyed steel in original conditions. This fact has been documented [12] as a combination that significantly favors the resistance to fracture of these welded joints, achieving complete penetration of both welding beads, resulting in adequate mechanical behavior.

In both joints, a significant fact is derived from $\mathrm{Q}_{\text {net}}$, when the value is medium $\left(0.374 \mathrm{~kJ} \cdot \mathrm{mm}^{-1}\right)$, the fracture resistance and the elongation percentage are improved, but the UTS decreases; on the other hand, the behavior with high $\mathrm{Q}_{\text {net }}$ value $0.523 \mathrm{~kJ} \cdot \mathrm{mm}^{-1}$ increases the UTS nonetheless reduces the resistance to fracture and deformation. In addition to this behavior, it is important to point out that the studied mechanical properties of the original steel are exceeded with the referred values [7], [8], therefore $Q_{\text {net }}$ and the residence time at high temperature of the electrode were preponderant in the resistance to fracture.

The stress/fracture relationship with respect to the $\mathrm{Q}_{\text {net }}$ of the analyzed samples is shown in Fig. 3b).
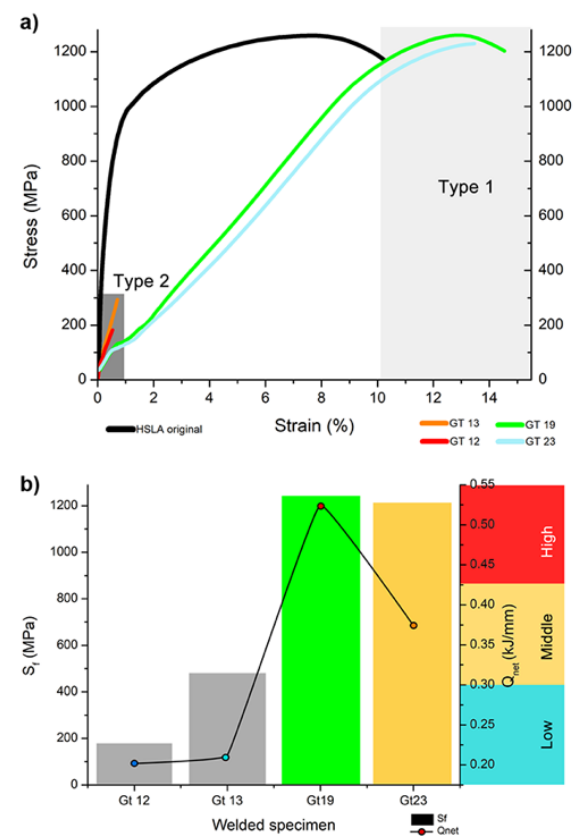

Fig. 3. a) Strain-stress curves of experimental steel in original conditions and GTAW welded joints, showing two types of behavior for fracture resistance, b) Relationship of stress to fracture with respect to $Q_{\text {net }}$, where it is observed that greater heat input, and better resistance to fracture.

TYPE 2 joints showed fracture in the area of the welded joint. The case of the specimen identified as GT13, whose combination of parameters was: $200 \mathrm{~A}, 13.5 \mathrm{~V}, 150^{\circ}$ and $480 \mathrm{~mm} \cdot \mathrm{min}^{-1}$, showed complete penetration of both welding beads triggered by the preheating of the pieces, resulting in a deficient $S_{\mathrm{f}}$ of $485 \mathrm{MPa}$, a result similar to that reported by [12], mainly associated with $Q_{\text {net }}$ 
$0.208 \mathrm{~kJ} \cdot \mathrm{mm}^{-1}$, which represents a decrease of $53.04 \%$ with respect to steel in original conditions [25].

Specimen GT12 showed incomplete penetration of the welding to the application of filler metal at room temperature, plus an inadequate combination of parameters (200 A, $12.7 \mathrm{~V}, 25^{\circ} \mathrm{C}, 480 \mathrm{~mm} \cdot \mathrm{min}^{-1}$ ). S $\mathrm{f}$ of $166 \mathrm{MPa}$ was obtained whose meagre mechanical performance is predominantly associated with the low $\mathrm{Q}_{\text {net }}\left(0.202 \mathrm{~kJ} \mathrm{~mm}^{-1}\right)$. This means an $83.9 \%$ reduction for $\mathrm{S}_{\mathrm{f}}$ and compared to seamless alloy steel.

\section{FRACTOGRAPHY}

The GT19 specimen kept the welded joint intact with the best fracture resistance $(1233 \mathrm{MPa})$, observing in it, both HAZ and the complete bead (Fig. 4 a-b), the failure in the base metal occurring 43.48 seconds after the test of tension, consequently, the surface topography is more fibrous [24], with brilliance and granular surface indicative of ductile fracture [11] with ridges and valleys more pronounced than the rest of the analyzed pieces; Likewise, the fibrous area is more evident and wide (FZ) with an area of $6.09 \mathrm{~mm}^{2}$ where the crack originated $(\mathrm{O})$, derived from a $0.144 \mathrm{~mm}^{2}$ macro cavity, is more evident and wide. The radial zone (RZ) is profuse $\left(13.58 \mathrm{~mm}^{2}\right)$ and indicative of the conditions of instability within the material during the applied force, whose fine marks indicate the direction to failure.

The crack $(\mathrm{G})$ had an extension of $11.23 \mathrm{~mm}$ with diagonal propagation to the specimen and directions of $40^{\circ}$ to $60^{\circ}$ cut by the origin of the fault $(\mathrm{O})$. The fractograph characteristics are similar to those reported by [11] and associated with the combination of parameters: $200 \mathrm{~A}, 12.7$ $\mathrm{V}, 25{ }^{\circ} \mathrm{C}$ and $180 \mathrm{~mm} \cdot \mathrm{min}^{-1}$, highlighting that the application of the filler metal at room temperature, the high Qnet $\left(0.523 \mathrm{~kJ} \cdot \mathrm{mm}^{-1}\right)$ along with $1.87 \mathrm{Wt} \%$ of $\mathrm{Ni}$ present in the chemical structure (of the base metal), improved the mechanical properties of the welded joints, exceeding the receiving conditions of the experimental HSLA steel [3], [11], [12], [14].

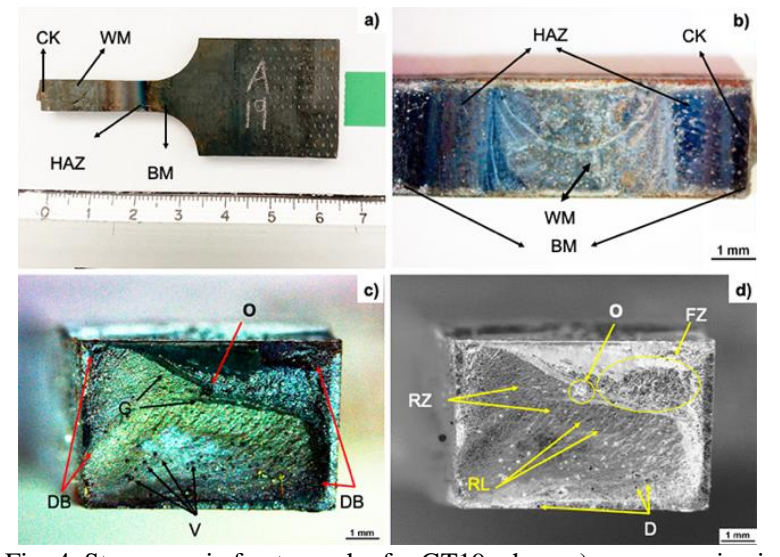

Fig. 4. Stereoscopic fractography for GT19 where a) macroscopic view with fracture in the base metal, b) longitudinal view at $6 \mathrm{x}$ of the weld bead to the base metal, c) transverse stereoscopy showing fracture in the base metal at $6.5 \mathrm{x}$.

Analogously, the GT23 specimen had the fracture in the base metal 42.17 seconds after applying the uniaxial stress (Fig. 5a), which resulted in a surface with a smoother texture and more flatness than the rest of the images analyzed (Fig.
$5 \mathrm{c})$, with homogeneous colors and higher light reflectivity [24]. The origin $(\mathrm{O})$ and size of the crack $(\mathrm{G})$ was $14.76 \mathrm{~mm}$ at $90^{\circ}$ from the edges of the specimen, whose fibrous zone (ZF) has an area of $0.377 \mathrm{~mm}^{2}$ where a cavity of $0.014 \mathrm{~mm}^{2}$ is observed. This was most accurately obtained using DPI as documented by [10], [13]. This methodology showed a topography resembling dimples (D), as well as fine marks indicating very discrete radial lines (RZ) in the direction of the fault (Fig. 5d). The crack propagation occurred at $50^{\circ}$ from the origin $(\mathrm{O})$, with trajectories of $48^{\circ}$ and $22^{\circ}$ in form of canals, showing ductile borders (DB), through DPI in clear areas (Fig. 5c-d) with the presence of voids (V) that indicate tension within the specimen; whose edges were maintained with $90^{\circ}$ relationships to each other.

All of aforementioned, induced by medium $\mathrm{Q}_{\text {net }}$ $\left(0.374 \mathrm{~kJ} \cdot \mathrm{mm}^{-1}\right)$ that favored fracture resistance, hence proving it to be a significant factor in the behavior of ductile fractures as reported by [11]. Likewise, the study suggests that the assembly temperature $\left(87.5^{\circ} \mathrm{C}\right)$ influenced the hardening of the specimens decreasing the elongation by $2 \%$, with respect to the GT19 joint, but significantly exceeding the deformation of the steel in the receiving condition.

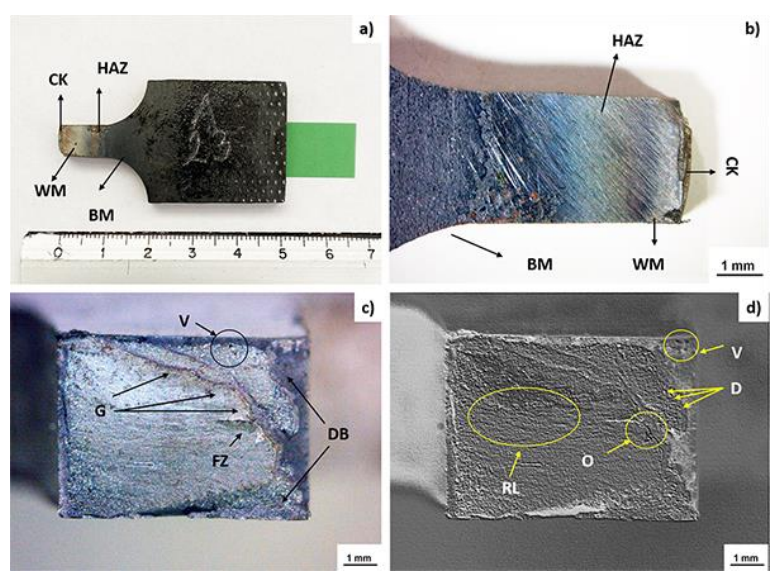

Fig. 5. Stereoscopic fractography for GT23 where a) macroscopic view of the arm is shown at the middle of the reduced section length,

b) longitudinal view at $6.5 \mathrm{x}$ with fracture in the HAZ, c) transverse view at $6.5 \mathrm{x}$ showing brittle fracture in the base metal.

Now, the specimens with TYPE2 behavior, GT12 and GT13 showed instantaneous elastic deformation in the melted metal, where failures occurred.

The first case has a defect in the trajectory of the robotic arm during the welding process, since the first pass torch and application of the filler metal happened properly, generating a first bead with an average thickness of $0.79 \mathrm{~mm}$, filling the root (Fig. 6c). The second pass (2P) of the filler metal was applied with a lateralized path on the base metal unable to enter the space between the coupons (Fig. 6b) [6]. This defect was caused by improper programming of the welding robot associated with the robotic arm kinematics; whose tolerances were not considered.

The first welding step (1P) is observed in the Fig. 6, where the melted metal with macrocavities (MC) in central orientation and horizontal lines perpendicular to the front and back of the specimen, with well-defined granular morphology is observed. Moreover, ductile edges (DB) are observed at the ends of the weld, with a delineation next to 
the HAZ. Which according to [11], corresponds to a ductile fracture associated with the $\mathrm{Q}_{\text {net }}$ and its conjugate parameters, with emphasis on the travel speed $\left(480 \mathrm{~mm} \cdot \mathrm{min}^{-1}\right)$.

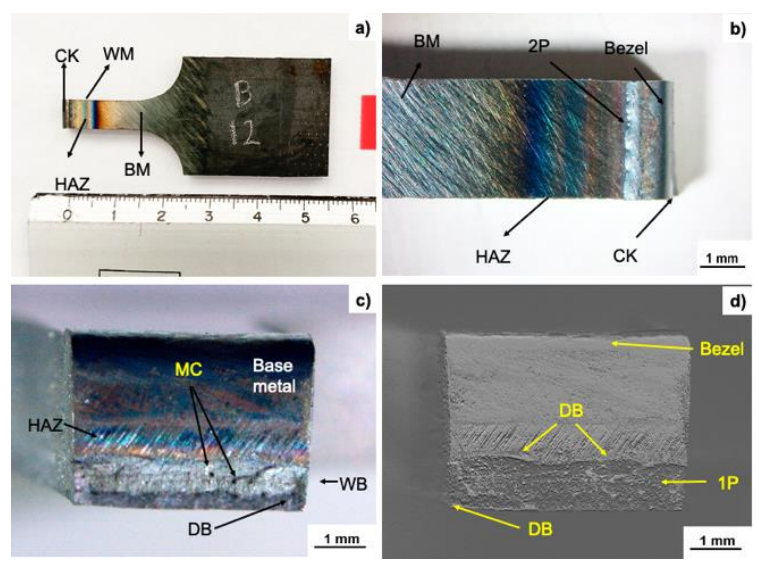

Fig. 6. Fractography for GT12 joint where a) macroscopic view of GT12 joint with fracture in the weld, b) longitudinal view at $6.5 \mathrm{x}$ of the area of the weld bead at the fracture, c) transverse shot at $6.5 \mathrm{x}$ of the weld bead where it is observed lack of penetration.

Finally, the specimen identified as GT13 had complete fusion and penetration of both welding passes (Fig. 7), where the failure occurred within 13.38 seconds of starting the tension test. As a result, the surface of the fracture shows a rougher texture (Fig. 7c), as well as a wider gamma of light-dark where the reflectivity of the light is diverse (Fig. $7 \mathrm{c}-\mathrm{d}$ ). The silver color of the fractured melted metal can be seen (WBC), an area that resembles the coalescence of voids (V) and dimples (D). In this case, the DPI provided the effective view [13] to determine the origin of the fracture: a macro cavity (MC) of $0.103 \mathrm{~mm}^{2}$ can be observed next to the fibrous zone of $1.66 \mathrm{~mm}^{2}$ (FZ) (Fig. 7) where it is presumed, the fault $(\mathrm{O})$ was nucleated. Striations can be observed in the direction of the fracture (central direction to the specimen), divided by the welding beads (1P, 2P), the first being the one with the greatest deformation and origin of the fault, with thick topography lines that resemble radial lines (LR) and ductile edges at the root of the weld with the presence of micro hollows (MH).

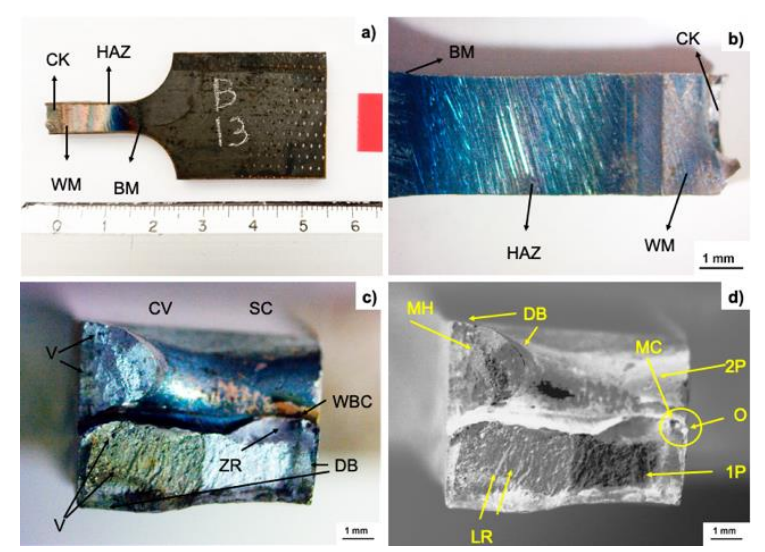

Fig. 7. Stereoscopy of the GT13 joint where a) in macroscopic view the half of the GT13 joint with fracture in the weld bead is observed, b) at $6.5 \mathrm{x}$ the HAZ and the fracture in the weld bead are shown in longitudinal view, c) in cross-sectional view shows lack of penetration with crack in the melted metal.

The main crack had $8.06 \mathrm{~mm}$ long dimension, with a secondary one of $2.3 \mathrm{~mm}$; while the second pass of the filler metal shows a $4 \mathrm{~mm}$ long and $1.33 \mathrm{~mm}$ deep depression (which replaces the crown) with undercut characteristics (SC) and an area with macro cavities (CV) and micro holes (V) with ductile boundaries (DB) $\left(5.1 \mathrm{~mm}^{2}\right.$ area), indicating coalescence of microcavities. According to literature [6] [24], this is the most common micro-mechanism of failure in alloys with higher resistance, due to material decohesion, stress concentrators or discontinuities [14], [24].

\section{CONCLUSIONS}

$\mathrm{Q}_{\text {net }}$ is a factor that has a decisive influence on the resistance to fracture. It was determined that the greater $Q_{n e t}$ increases the resistance to fracture and the medium and high values of $Q_{\text {net }}\left(0.374-0.523 \mathrm{~kJ} \cdot \mathrm{mm}^{-1}\right)$ which consequently proved advantageous for the mechanical properties of these welded joints, surpassing the characteristics of steel in original conditions.

Another relevant factor in the study was the assembly temperature (preheating), which turned out to be inadequate when the $\mathrm{Q}_{\text {net }}$ is medium-high, since it reduces the percentage of deformation. Therefore, it is suggested to apply both welding passes at a wire feed rate of $7.2 \mathrm{~mm} \mathrm{~min}^{-1}$ and at room temperature with a travel speed of $180 \mathrm{~mm} \cdot \mathrm{min}^{-1}$.

The combinations of parameters $200 \mathrm{~A}, 12.7 \mathrm{~V}, 25^{\circ} \mathrm{C}$ and $180 \mathrm{~mm} \cdot \mathrm{min}^{-1}$ and $250 \mathrm{~A}, 13.3 \mathrm{~V} 87.5^{\circ} \mathrm{C}$ and $330 \mathrm{~mm} \cdot \mathrm{min}^{-}$ ${ }^{1}$ are those that work properly to guarantee the quality of the welded joints in the event of fracture in the base metal, which included central stresses, fibrous zones of reduced areas $\left(0.377-6.09 \mathrm{~mm}^{2}\right)$, edges and ductile fractures.

The DPI helped determine the origin of the faults with greater precision, as well as having a clear visualization of holes and cavities. Low $Q_{\text {net values }}\left(0.200 \mathrm{~kJ} \cdot \mathrm{mm}^{-1}\right)$ and specimen GT12 parameter combinations (200 A, $13.5 \mathrm{~V}$, $25^{\circ} \mathrm{C}$ and $480 \mathrm{~mm} \cdot \mathrm{min}^{-1}$ ) and GT13 (200 A, $13.5 \mathrm{~V}, 150{ }^{\circ} \mathrm{C}$ and $480 \mathrm{~mm} \cdot \mathrm{min}^{-1}$ ), should be discarded given they present defects and undesirable behaviors in the welded joint.

\section{ACKNOWLEDGMENT}

The authors thank the Center for Engineering and Industrial Development (CIDESI) and the National Council of Science and Technology (CONACyT) for the support and financing of this research. We also express our appreciation and gratitude to Dr. María Verónica Estrella S. We thank the Tecnológico Nacional de México, perticulary the campus Estado de México, as well all those who participated in this disclosure.

\section{REFERENCES}

[1] Kumar Jena P., Sentil P., Kumar K. S. Effect of tempering time on the ballistic performance of a high strength armour steel. Journal of applied research and technology, 2016; 14(1): 47-53.

[2] Cimpoeru S. The Mechanical Metallurgy of Armour Steels, Technical Report. Commonwealth of Australia, Melbourne. pp. 2, 14-17, 2016.

[3] García Jacobo R. Efecto de la Potencia laser del proceso HLAW en uniones de acero HSLA 550 sobre la microestructura y propiedades mecánicas. 7 Junio, 2019.

[4] Belzunce F. Aceros y fundiciones: estructuras, transformaciones, tratamientos térmicos y aplicaciones, Oviedo, 2001. 
[5] American Welding Society (AWS). D1.1, Structural Welding Code. American Welding Society, 2010.

[6] American Welding Society (AWS). Welding Inspection Technology (WIT). AWS, Miami Florida, 2000.

[7] Guzmán Flores I., Vargas Arista B., Gasca Domínguez J., Cruz González C., Pardo Villasana J. Effect of Torch Weaving on the Microstructure, Tensile and Impact Resistances, and Fracture of the HAZ and Weld Bead by Robotic GMAW Process on ASTM A36 Steel, Soldagem \& Inspeção, 2017; 22(1): 73-76.

[8] Hongliang Ming, Jianqiu Wang, En-Hou Han. Comparative study of microstructure and properties of low-alloy-steel/nickel-based-alloy interfaces in dissimilar metal weld joints prepared by different GTAW methods. Materials Characterization, 2018; 138: 186-196.

[9] Vargas Arista B., Albiter A., García Vázquez F., Mendoza Camargo O. Effect of natural aging on the microstructural regions, mechanical properties, corrosion resistance and fracture in welded joints on API5L X52 steel pipeline. Revista de Metalurgia., 2014; 50(3): 2-9.

[10] Camargo O., Vargas B., Camargo J.M. Digital processing of fractographic images for welded joints on micro alloy steel API5L-X52 aged. IEE Latin America transactions, 2013; 11(1): 172-176.

[11] Vargas Arista B., Mendoza Camargo O., Zaragoza Rivera I. P., Medina Flores A., Cuevas Salgado A., Garfias García E., García Vázquez F. Influence of heat input on the charpy ductile fracture behavior of reheated HAZ in GMAW multilayer welded joints on HSLA steel using digital fractographic analysis. Revista de Metalurgia, Junio 2019; 55(2): $1-10$.

[12] Fuentes A., Vargas B., Cruz C.E., Estrella V., Zaragoza I.P. Efecto del calor de entrada sobre la microestructura y microdureza en uniones soldadas GTAW-P robotizadas para acero HSLA. Quimica hoy, 2020; 10(2): 815 .

[13] Da-Hai Xia, Shizhe Song, Lei Taoc, Zhenbo Qin, Zhong Wu, Zhiming Gao, Jihui Wang, Wenbin Hua, Yashar Behnami and, Jing-Li Luo. Reviewmaterial degradation assessed by digital image processing. Fundamentals, progresses, and challenges, Journal of Materials Science \& Technology, 2020; 53:146-162.

[14] Korsmik R., Klimova-Korsmik O., Valdaytseva E., Udin I Investigation of cracking causes during multi-pass laser cladding of heatresistant single crystal nickel alloy. Procedia CIRP, 2020; 94 314319.

[15] Boob A. N., Gattani G. K. Study on Effect of Manual Metal Arc Welding Process Parameters on Width of Heat Affected Zone (HAZ) for Ms 1005 Steel. International Journal of Modern Engineering Research (IJMER), June 2013; 3:1493-1500.

[16] Bailey N. Weldability of ferritic steels. In Woodhead Publishing Series in Welding and Other Joining Technologies, Cambridge England, 1994, pp. 1-44.

[17] Luo W. The corrosion resistance of $0 \mathrm{Cr} 19 \mathrm{Ni} 9$ stainless steel arc welding joints with and without arc surface melting. Materials science \& Engineering, pp. 1-7, 2003.

[18] American Society for Testing and Materials. ASTM E415-14, Standard test Method for analysis of carbon and low-alloy steel by spark atomic emission spectrometry. ASTM International, West Conshohocken, 2014.

[19] American Welding Society. AWS A5.18/A5, Specification for carbon steel and rods for gas shielded arc welding. ANSI AWS, Miami Florida, 2005.

[20] Singh R. Applied Welding Engineering (Second Edition). ButterworthHeinemann, pp. 131-162, 2016.

[21] Singh R. Applied Welding Engineering (Third Edition). Butterworth Heinemann, pp. 125-155, 2020.

[22] American Society for Testing and Materials. ASTM E-8-E-8M-13, International standard test methods for tension testing of metallic materials. ASTM, West Conshocken, 2013.

[23] Le Jolu T., Morgeneyer T. F., Denquin A., Sennour M., Laurent A., Besson J.S., Gourgues-Lorenzon A. Microstructural Characterization of internal Welding Defects and their effect on the tensile behavior of FSW joints of AA2198 Al-Cu-Li alloy. Metallurgical and Materials Transactions A, Springer Verlag/ASM International, 2014; 45:55315544.

[24] Kathleen M. ASM Handbook Fractography, Vol. 12, Ohio USA: ASM International, 2009.

[25] Honggang Dong, Xiaohu Hao y Dewei Deng. Effect of welding heat input on microstructure and mechanical properties of HSLA steel joint Metallography, Microstructure and Analysis, vol. 3, pp. 138-146, 2014.

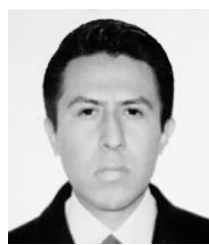

Orión Leyva López from Estado de México, México. Recived Bachelor of Mechatronic engineer specialty in automotive systems in Universidad del Valle de Mexico (UVM) in México in 2016. He is student of Masters of Science of the Engineering in Instituto Tecnológico and he received the national scholarship for quality postgraduate. Experience in the assembly of Glider-type submarines as professional practices in the Center for research and advanced studies (CINVESTAV) of the Instituto Politécnico Nacional in Mexico City.

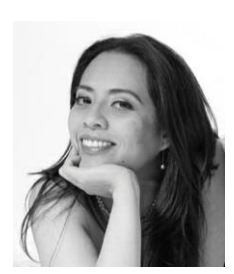

Graciela Rosel received the B.S. degree in engineering in software development and Master in Engineering Science with a specialty in materials science at the Tecnológico Nacional de México. She has studies in robotics, automation, art, and design, which has allowed her work on projects where art and science combined. Her career includes interventions in public and private institutions for project optimization, software development projects, logical and physical database designs, as well as data science and artificial intelligence applied to industrial quality. To date, she has worked as a technology, software, and data consultant in private initiative with attention to franchises. Her research interests include data processes and applications for optimization of materials and data science focused on the industry. She has published various papers on the science and characterization of metallic materials. In 2017 she received the national scholarship for quality postgraduate. She is part of the group of women leaders in STEM (Mexico-US binational project) with impact in 79 countries, having a mentor role to bring young women closer to Science, Technology, Engineering and Mathematics.

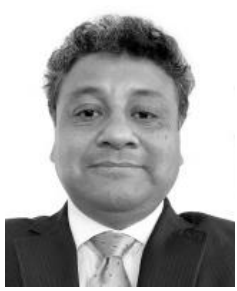

Dr. Hugo Gamez Cuatzin from México. He obtained a bachelor's degree in the technological institute of Orizaba in electronic engineering, his master's degree was studied at the Center for Research and advanced studies of the IPN in the area of electrical engineering in Mexico City and his doctorate was at Ins. National des sciences appliquees de Lyon France in the electronics area.

His research interests are focused on industrial applications with applied technology, characterization of materials, optical and electronic properties, fuzzy logic, and finite element.

$\mathrm{He}$ is a researcher and he has extensive academic experience, more than twenty international publications, presentations and interventions in the public sector in alliances with the industrial private sector, where he has had an outstanding career. He is currently a director at the center for engineering and industrial development (CIDESI). 